\title{
Three-Dimensional Image Integration: A First Experience with Guidance of Atrial Fibrillation Ablations
}

\author{
JASON RUBENSTEIN, M.D. and ALAN KADISH, M.D.
}

From Northwestern University, Feinberg School of Medicine, Chicago, Illinois, USA

\section{Editorial Comment}

The treatment of atrial fibrillation (AF) can be challenging, with a rate control strategy not being optimal for all patients and antiarrhythmic drugs frequently ineffective and possessing serious adverse effects. A fluoroscopic or electroanatomic catheter-based approach is rapidly becoming one of the preferred treatments of $\mathrm{AF}^{1-3}$ However, success rates are still not ideal and complications due to damage of extra thoracic structures remain a problem. ${ }^{1}$ Also of concern is the significant ionizing radiation exposure during the prolonged fluoroscopy required to delineate the complex anatomy of the left atrium and pulmonary veins, even with advanced techniques to minimize exposure. Total fluoroscopy duration for $\mathrm{AF}$ ablations is typically 8 -fold higher than atrioventricular nodal reentrant tachycardia ablations, averaging over 60 minutes of fluoroscopy time, with radiation exposure in the 1.0-1.5 Gy range. ${ }^{4}$ One of the major promises of using integratedmodality navigation systems such as this for AF ablation is faster, more accurate catheter navigation, reduced complications, and diminished fluoroscopy use.

In view of the complex and variable anatomy of cardiac structures and pulmonary veins, many of which remain invisible to fluoroscopy, the addition of further, more accurate imaging modalities are likely to improve ablation success and safety. ${ }^{5,6}$ While three-dimensional (3D) mapping techniques using magnetic or electrical localizing systems in the modern electrophysiology laboratory are extremely useful and are currently in widespread clinical use, they require catheter manipulation to identify geometry and do not provide independent anatomic information. Both magnetic resonance (MR) imaging ${ }^{7,8}$ and computed tomography (CT) scanning ${ }^{9,10}$ have been shown prior to be suitable for delineating the left atrial anatomy and assisting with catheter navigation. However, it is not yet clear which imaging modality is superior for mapping of the left atrium and other cardiac structures; certainly navigation and imaging systems that allow the use of either format will be advantageous.

In this issue, Dong et al. ${ }^{11}$ report on their initial experience in using integrated cardiac MR and computed axial tomography (CT) images to guide catheter ablation of AF. They used a new image integration software CartoMerge (Biosense Webster, Inc., Diamond Bar, CA, USA) that can accept images from either MR or CT modalities. ${ }^{11}$ In this study population, half of the 16 patients were imaged utilizing 64-slice

J Cardiovasc Electrophysiol Vol. 17 pp. 467-468 May 2006.

Address for correspondence: Alan Kadish, M.D., Northwestern University, Feinberg School of Medicine, 251 E. Huron, Feinberg Pavilion Suite 8-536, Chicago, IL 60611, USA. Fax: 312-926-0607, E-mail: akadish@northwestern.edu

doi: 10.1111/j.1540-8167.2006.00449.x
$\mathrm{CT}$, and half 1.5-T MR, all within 1 day prior to the AF ablation. All preprocedure image acquisition was done within 24 hours of ablation. MR imaging provided slice thickness of $1.6 \mathrm{~mm}$, while the CT produced $0.5 \mathrm{~mm}$ thick images. A semiautomated, offline process allowed the identification of the structures (left atrium, pulmonary veins) of interest, and 3D surfaces were produced.

The key step prior to the clinical use of 3D surfaces is image registration. The current standard computer navigation tool used during AF ablations is the electroanatomic map. Electroanatomic mapping systems detect the tip of the ablation catheter in real time, and generate a surface that describes the catheters maximum bounds of motion that result in endocardial contact, as determined by tip electrode. ${ }^{12}$ This will provide an estimate of the interior space of the cardiac structure that the catheter is in, limited by the number of positions through which the catheter travels. The surfaces from CT or MR can only be useful during an ablation if they can be accurately overlaid with the electroanatomic mapping, so that real-time catheter positions can be shown in precise relation to the 3D surfaces. Inaccuracies in image registration can compound natural error intrinsic to an imaging modality. This particular software uses a combination of static landmarks as well as estimations of the pulmonary veins by catheter pullback to reduce image registration error. A software algorithm performs a fit to set registration to create the smallest average distance between the two data sets.

This study allowed the image-based map to be used to guide RF energy delivery during ablation only if the CT/MR surface disagreed with the electroanatomic map by less than $3 \mathrm{~mm}$. During the image registration process, the accuracy of the registered images was further verified by assessing the ability to navigate the catheters into the pulmonary veins and the left atrium appendage under fluoroscopy, and monitoring the catheter tip on the 3D image data set. The authors reported that they were able to achieve alignment between either the CT or MR surface map and the electroanatomic map within $5 \mathrm{~mm}$ agreement $43 \%$ of the time using the pulmonary veins for alignment only, and this increased to $95 \%$ of cases with good agreement when also including landmarks for registration. The authors nicely demonstrated that image registration is crucial for accurate image integration in the electrophysiology laboratory.

Dong et al. ${ }^{11}$ reported that the average distance from the catheter tip by electroanatomic mapping to the rendered 3D surface from CT or MR (surface-to-point distance) was $3.05 \mathrm{~mm}$. There was no significant difference in this error between CT or MR modalities, despite higher resolution images obtained by CT. The surface-to-point error can be accounted for by an accumulation of error from the electroanatomic localization, CT or MR inaccuracies, registration error, and physiologic changes to the left atrium size and shape in the interim between imaging and procedure. This surface-to-point 
error compares well with previous animal studies that have been able to demonstrate approximately $2-3 \mathrm{~mm}$ accuracy. ${ }^{13}$ Although no gold standard is available to validate $3 \mathrm{D}$ image creation, the combination of techniques utilized by the authors to validate mapping accuracy suggests that the technique may be robust.

When reviewing outcomes from this initial experience, it is important to consider that this study enrolled a small number of patients to access the utility of this new technology, and no control group was included. Despite this limitation, several important clinical observations were made. Total fluoroscopy time was 75 minutes on an average per patient, 15 minutes on an average longer than the mean fluoroscopy time in some prior reports. ${ }^{1}$ Also of interest was the reported 6-month AF success rate in 10 of 16 patients $(63 \%)$. Previously reported success rates for standard AF ablations vary widely, and the number of patients included was too small to evaluate. ${ }^{1} \mathrm{No}$ complications were observed.

To our knowledge, this is the first report of experience using integrated electroanatomic mapping with MR or CT images in humans. While this initial experience with image-assisted catheter-based AF ablation is promising, there are several questions that must still be answered before widespread implementation. Does the additional data and guidance improve AF ablation success rates? Can it reduce both procedure time and fluoroscopy exposure? Does better anatomic information reduce pulmonary vein stenosis rates by allowing the placement of lesions further from the ostia? What level of precision in the surface-to-point dimension is necessary for safe and effective use of the technology? These questions will need to be answered with larger-scale outcome studies. With this initial experience, in the absence of a comparison group, the true clinical utility of the technique remains promising but unproved. However, the technique is intuitively useful, and the authors are to be commended for their attempt to validate image registration. As this technology matures, the accuracy of the left atrium surface map and the registration process will improve, which may well lead to improved success rates and shorter AF ablation procedure times.

\section{References}

1. Wazni OM, Marrouche NF, Martin DO, Verma A, Bhargava M, Saliba W, Bash D, Schweikert R, Brachmann J, Gunther J, Gutleben K, Pisano
E, Potenza D, Fanelli R, Raviele A, Themistoclakis S, Rossillo A, Bonso A, Natale A: Radiofrequency ablation vs antiarrhythmic drugs as firstline treatment of symptomatic atrial fibrillation: A randomized trial. JAMA 2005;293: 2634-2640.

2. Haissaguerre M, Jais P, Shah DC, Takahashi A, Hocini M, Quiniou G, Garrigue S, Le Mouroux A, Le Metayer P, Clementy J: Spontaneous initiation of atrial fibrillation by ectopic beats originating in the pulmonary veins. N Engl J Med 1998;339:659-666.

3. Pappone C, Rosanio S, Oreto G, Tocchi M, Gugliotta F, Vicedomini G, Salvati A, Dicandia C, Mazzone P, Santinelli V, Gulletta S, Chierchia S: Circumferential radiofrequency ablation of pulmonary vein ostia: A new anatomic approach for curing atrial fibrillation. Circulation 2000;102:2619-2628.

4. Lickfett L, Mahesh M, Vasamreddy C, Bradley D, Jayam V, Eldadah Z, Dickfeld T, Kearney D, Dalal D, Luderitz B, Berger R, Calkins $\mathrm{H}$ : Radiation exposure during catheter ablation of atrial fibrillation. Circulation 2004;110:3003-3010.

5. Asirvatham SJ, Bruce CJ, Friedman PA: Advances in imaging for cardiac electrophysiology. Coron Artery Dis 2003;14:3-13.

6. Kato R, Lickfett L, Meininger G, Dickfeld T, Wu R, Juang G, Angkeow P, LaCorte J, Bluemke D, Berger R, Halperin HR, Calkins H: Pulmonary vein anatomy in patients undergoing catheter ablation of atrial fibrillation: Lessons learned by use of magnetic resonance imaging. Circulation 2003;107:2004-2010.

7. Dickfeld T, Calkins H, Zviman M, Kato R, Meininger G, Lickfett L, Berger R, Halperin H, Solomon SB: Anatomic stereotactic catheter ablation on three-dimensional magnetic resonance images in real time. Circulation 2003;108:2407-2413.

8. Raman SV, Ng VY, Neff MA, Sayar S, Sparks EA, Nelson SD, Ferketich AK, Wooley CF: Volumetric cine CMR to quantify atrial structure and function in patients with atrial dysrhythmias. J Cardiovasc Magn Reson 2005;7:539-543.

9. Solomon SB, Dickfeld T, Calkins H: Real-time cardiac catheter navigation on three-dimensional CT images. J Interv Card Electrophysiol 2003;8:27-36.

10. Burgstahler C, Trabold T, Kuettner A, Kopp AF, Mewis C, Kuehlkamp $\mathrm{V}$, Claussen CD, Schroeder S: Visualization of pulmonary vein stenosis after radio frequency ablation using multi-slice computed tomography: Initial clinical experience in 33 patients. Int J Cardiol 2005;102:287291.

11. Dong J, Dickfeld T, Dalal D, Cheema A, Vasamreddy CR, Henrikson CA, Marine JE, Halperin HR, Berger RD, Lima JAC, Bluemke DA, Calkins H: Initial experience in the use of integrated electroanatomic mapping with three-dimensional MR/CT images to guide catheter ablation of atrial fibrillation. J Cardiovasc Electrophysiol 2006;17:459466.

12. Gepstein L, Hayam G, Ben-Haim SA: A novel method for nonfluoroscopic catheter-based electroanatomical mapping of the heart: In vitro and in vivo accuracy results. Circulation 1997;95:1611-1622.

13. Reddy VY, Malchano ZJ, Holmvang G, Schmidt EJ, d'Avila A, Houghtaling C, Chan RC, Ruskin JN: Integration of cardiac magnetic resonance imaging with three-dimensional electroanatomic mapping to guide left ventricular catheter manipulation: Feasibility in a porcine model of healed myocardial infarction. J Am Coll Cardiol 2004;44:2202-2213. 